\title{
Avaliação: Para que te quero? \\ Um olhar voltado para além do educar e cuidar
}

\section{Assessment: What do I want you for? \\ A look beyond educating and caring}

Aline Dias Nascimento, graduada em Pedagogia pela Universidade Federal de Santa Catarina (UFSC) e pós-graduada em Psicopedagogia pela Universidade de Passo Fundo (UPF), é mestre em Educação e Currículo pela Pontifícia Universidade Católica de São Paulo (PUC-SP).

Rita Oliveira André, graduada em Pedagogia e Serviço Social pela Pontifícia Universidade Católica de São Paulo (PUC-SP), é pósgraduada em Clínica Interdisciplinar do Bebê e Psicopedagogia e mestre em Educação e Currículo (PUC-SP), com especializações em Autismo (Instituto Language/Universidade de Lyon), Supervisão e Direção Escolar (PUC-SP), Gestão de Projetos (FGV) e Gestão de Pessoas (Fundação Dom Cabral).

\section{Resumo}

0 presente artigo demonstra e discute a importância de avaliar a qualidade da educação ofertada a bebês e crianças, atrelada à constatação de que a formação do professor necessita ser ressignificada e a concepção pautada em sujeitos ativos. Neste sentido, o currículo deve ser traçado por práticas que prevaleçam às suas ações e características, superando aquelas que se pressupõe importante eles saberem. Desse ponto de vista, a utilização dos Indicadores de Qualidade da Educação Infantil Paulistana (2016), fundamentado no princípio da participação, mostra que o instrumento contribui para a discussão institucional e que os resultados da autoavaliação são interessantes para a própria gestão. Conclui-se que o processo potencializa uma qualidade negociada entre unidade, família e a comunidade. Palavras-chave: Autoavaliação Institucional. Indicadores de qualidade. Afetividade. Formação de Professores. Currículo. 


\begin{abstract}
This paper demonstrates and discusses the importance of assessing the quality of education offered to infants and children, connected to the fact that teacher training needs to be resignified and its conception has to based on active subjects. Therefore, the curriculum should be based on practices that prevail to their actions and characteristics, overcoming those assumed to be important for them to know. From this point of view, the use of the Quality Indicators for the São Paulo Early Childhood Education System (2016), grounded on the principle of participation, shows that this mechanism contributes to the institutional debate, and that the results of the self-assessment are interesting for the management itself. The conclusion is that the process enhances a quality negotiated between unity, family and community.

Keywords: Participatory Institutional Assessment. Quality Indicators. Affection. Teacher training. Curriculum.
\end{abstract}

$\mathrm{Na}$ Educação Infantil algumas conquistas possibilitaram um crescente número de crianças frequentando as creches e préescolas, presença esta assegurada pela Constituição Federal, de 1988, pelo Estatuto da Criança e do Adolescente (ECA), de 1990, e pela Lei de Diretrizes e Bases da Educação Nacional (LDBN), de 1996. Esses documentos ratificam a Educação Infantil como dever do Estado e como um direito social da criança.

Embora os avanços legais tenham integrado a creche ao sistema educacional e reconhecido a Educação Infantil como a primeira etapa da Educação Básica, os bebês e as crianças pequenas ainda são "invisíveis" em muitas das propostas político-pedagógicas, nas políticas públicas e no currículo das instituições que formam os profissionais que atuam com a primeira infância.

Contudo, o Ministério da Educação (MEC) desempenhou um papel importante promovendo discussões sobre a qualidade das condições das instituições de Educação Infantil e publicando documentos norteadores de práticas pedagógicas.

Esses documentos apontam para a superação de possíveis entraves que hábitos tradicionais e práticas arraigadas muitas vezes trazem para dentro das instituições escolares. Sendo assim, 
posições, de interesses, de perspectivas; e, ainda, para o fortalecimento das relações internas (SÃO PAULO, 2014, p. 26).

Ações concretas vêm se desenhando na busca incansável por ressignificar o olhar das unidades educacionais para a avaliação e o planejamento como parte das estratégias necessárias para o desenvolvimento de um trabalho pedagógico de qualidade. Assim como ações compartilhadas com a família e a comunidade são parâmetros para uma qualidade nas relações no interior das instituições de Educação Infantil.

Em consonância a essas ações o artigo busca discutir como a experiência de autoavaliação possibilita à unidade educacional um entendimento além do cuidar e educar bebês e crianças.

Busca-se verificar como o processo de autoavaliação institucional participativa contribui com o processo coletivo de discussão no âmbito da creche, fortalecendo a ideia de formação continuada no ambiente de atuação dos(as) profissionais que atendem os bebês e as crianças.

Nesse sentido, uma revisão de pesquisas (1996-2003) aponta para preocupações com a qualidade da Educação Infantil no Brasil e revela problemas em aspectos importantes atrelados ao desenvolvimento integral das crianças em dimensões que abrangem formação dos professores, condições de infraestrutura, práticas educativas, relação com as famílias e o ambiente formador, ou seja, propostas pedagógicas e currículo.

Anna Bondioli (2004) menciona a qualidade educativa numa perspectiva abrangente, não só como oferta do serviço à família, mas no sentido público dessa oferta, enquanto responsabilidade coletiva.

\section{[...] refiro-me ao conjunto de aspectos próprios de uma creche que a qualificam como ambiente educativo, um ambiente particular que tem como objetivo a garantia de condições positivas de crescimento e de desenvolvimento para as crianças que nele são recebidas e que fornecem às famílias garantias justamente em relação a esse desenvolvimento (BONDIOLI, 2004, p. 142).}

Buscando compreender o que pais, professores, diretores, funcionários e crianças concebem como uma educação de qualidade para as crianças pequenas, um estudo' procurou captar as vozes desses sujeitos e mostrou que os critérios de qualidade não são iguais para todas as pessoas - e como os diferentes segmentos elegem critérios distintos para defini-las.
1. Consulta sobre Qualidade da Educação Infantil (2011), desenvolvida em quatro estados com apoio da Campanha Nacional pelo Direito à Educação, do Movimento Interfóruns de Educação Infantil (MIEIB) e da Fundação Carlos Chagas. 
Considerando a especificidade da Educação Infantil à luz das experiências realizadas por Bondioli, se faz necessário salientar a importância da participação e colaboração, entre as equipes que trabalham nas unidades, na gestão dessas redes e os pesquisadores das universidades.
Esses estudos confirmam sua importância como subsídios investigativos para a aplicação dos processos avaliativos nos contextos brasileiros, no sentido sugerido de tornar a avaliação a serviço da participação, e para "fazer" a qualidade avaliando de forma participativa.

Nessa discussão, e acreditando no processo que colabora para o fortalecimento da gestão democrática e promove ainda mais o diálogo entre a rede, a experiência brasileira optou por uma autoavaliação institucional participativa com o uso do documento Indicadores da Qualidade na Educação Infantil, publicado pelo MEC (2009) - considerado um instrumento avaliativo potente no sentido de contribuir com as reflexões dos educadores e demais segmentos envolvidos com a educação de bebês e crianças pequenas.

Confirmadas as contribuições do processo coletivo de discussões, com a experiência de utilização de indicadores para avaliar as condições do atendimento nas unidades diretas e conveniadas, um grupo da rede municipal de São Paulo engajado num projeto de avaliação no contexto das unidades da Educação Infantil previu a elaboração de um documento próprio da rede paulistana a partir do documento publicado pelo MEC (2009).

0 documento resultante - Indicadores de Qualidade da Educação Infantil Paulistana² - apresentou nove dimensões de qualidade, duas a mais do que o documento nacional (MEC, 2009), sendo: Participação, escuta e autoria de bebês e crianças; Relações étnico-raciais e de gênero.

Neste artigo, busca-se em especial explicitar a importância da dimensão Participação, escuta e autoria de bebês e crianças.

A abordagem dessa dimensão vem corroborar a formação dos profissionais que interagem com as crianças pequenas,
2. As duas dimensões acrescidas ao documento resultaram de um percurso de reflexões a partir dos documentos produzidos pela rede. No texto da versão final 2016, a ordem das dimensões foi modificada e o título definitivo adotado foi "Indicadores de Qualidade da Educação Infantil Paulistana". 
contribuindo em suas práticas, suscitando o diálogo, fortalecendo as ações baseadas em princípios como respeito, colaboração e confiança. A busca da disponibilidade intencional do professor garante a participação e a autoria infantil, proporcionada por um currículo que dê visibilidade às ações infantis, possibilitando uma avaliação construída com e para os bebês e as crianças pequenas.

Desta feita, há a necessidade de que, durante o planejamento, o exercício de escuta venha à tona e seja eixo norteador das intenções declaradas pelos educadores da primeira infância. Assim, conforme Corsino (2009), "planejar inclui escutar a criança para poder desenhar uma ação que amplie as suas possibilidades de produzir significados"; e, construindo a ação dessa maneira, entendem-se as crianças como capazes de se tornarem protagonistas no projeto educacional.

\footnotetext{
(...) torna-se indispensável possibilitar aos bebês e às crianças pequenas que se expressem livremente, criem seus espaços, seus desenhos, suas fantasias, suas histórias, vivenciem o contato com elementos da natureza, que possam escolher seus parceiros e criar enredos para as suas brincadeiras, ou seja, torná-las visíveis em seu próprio contexto, por meio de currículo que garanta seus direitos, de modo que cada palavra esteja impregnada pela afetividade e a intencionalidade pedagógica pelo saber lúdico. (ANDRÉ, 2016, p. 124).
}

Estudos e pesquisas sobre o desenvolvimento dos bebês, o reconhecimento das competências e das necessidades básicas das crianças de 0 a 3 anos vêm ocorrendo há décadas no Instituto Emmi Pikler, situado em Budapeste, na Hungria. A dra. Pikler defendia a segurança afetiva e uma motricidade livre como base do seu trabalho com os bebês, elaborado a partir de três funções principais: o acolhimento e cuidados com o bebê, a pesquisa sobre o processo de desenvolvimento do bebê concatenado com a função institucional e a formação e supervisão permanente das educadoras que se ocupam dos bebês.

Na formação dos educadores, assim como na prática de atendimento aos bebês, são enfatizados aspectos necessários à "nutrição afetiva", dentre os quais a constância da educadora, que ao atender o bebê deve conversar informando ou antecipando-lhe o que acontece ao seu redor, construindo possibilidades interativas e usando a prosódia como estratégia comunicativa. 
de cooperar constituem, igualmente, aspectos da 'transformação para melhor'. (Bondioli, 2004, p. 15).

A aplicação da autoavaliação remete todos os setores da unidade às reflexões de suas práticas, maneira esta que ora leva a equipe gestora a demonstrar resistência, por ser avaliada por outrem "desqualificado" das atribuições pedagógicas, ora suscita discussões e abre as sugestões para as mudanças.

Dito dessa forma, constata-se a importância do envolvimento da equipe gestora disseminando esse tipo de proposta avaliativa, tão recente em nossas práticas brasileiras. Ainda que o documento proponha uma metodologia fundamentada na participação de todos os segmentos, é a maneira de conduzir o processo que vem a ser decisiva para o resultado do processo participativo.

Considerando os princípios da participação preconizada pelo documento e o potencial formativo que se apresenta para as discussões sobre a qualidade com todos os professores e comunidade escolar, optou-se pela pesquisa qualitativa que norteia as observações realizadas nas creches, traçando aproximações com os sujeitos, tendo o ambiente como principal fonte de coleta dos dados, o que possibilita ao observador, segundo André (2013), "apreender a sua visão de mundo, isto é, o significado que eles atribuem à realidade que os cerca e às suas próprias ações" (p. 31). A coleta dos dados resultou da participação dos sujeitos em entrevista, professores, equipe gestora e mães, que relataram suas percepções relacionadas ao processo de discussão coletiva proposta na metodologia do documento. Para o estudo das observações, o registro e o material coletado de reuniões são etapas importantes para a análise dos dados.

A participação, vista como um princípio que sustenta o processo democrático proposto na metodologia do documento para avaliar os indicadores de qualidade, coincide com o estudo de Licínio Lima (2011), que, ao mesmo tempo que propõe, distingue os tipos de participação em uma pesquisa. Essa distinção auxilia as unidades a mapearem a participação dos sujeitos envolvidos, suas decisões e as deliberações resultantes do processo de avaliação. São elas: participação ativa, participação reservada e participação passiva.

Destacamos na aplicação da autoavaliação a participação nos estudos de Licínio Lima buscando relações com a dimensão que ilumina as discussões sobre o item "Participação, escuta e autoria de bebês e crianças", no qual concentram-se as preocupações com a formação dos professores e os dados das pesquisas sobre 
a realidade no cotidiano das instituições de Educação Infantil apontados inicialmente neste texto. Em outras palavras, a unidade pode se indagar quanto ao envolvimento dos sujeitos com o tema e deve estar atenta às decisões do grupo de professores na autoavaliação, na forma de conduzirem o processo de discussões, na escuta aos pais e nos seus próprios saberes práticos, estabelecendo um olhar investigativo às aprendizagens dos bebês e das crianças pequenas no cotidiano das unidades.

0 presente artigo vem mostrar com essa experiência um retrato de uma das inúmeras possibilidades de participação que um processo de avaliação em espaços coletivos pode revelar, no olhar de professores de bebês e crianças, pais e comunidade, e o potencial formativo que a revela.

Busnel (1997) destaca que os bebês sabem o que é bom para eles e que é importante conhecer seus desejos e respeitá-los. "É preciso considerá-lo como um interlocutor que compreende e escuta. 0 bebê não é um adulto imaturo; é um bebê perfeito em seu próprio nível de desenvolvimento". (BUSNEL,1997, p. 11).

Compreender as necessidades do bebê é o primeiro grande encontro no qual são estabelecidos diálogos entre ele e a mãe, sua família e educadores. É preciso que o respeito aos vínculos que essa criança estabelece em tenra idade seja mantido até que ela possa, por si só, indicar autonomia.

A infância tem sentido e significado nela mesma, não sendo um momento de preparação para outras etapas da vida, mas de vivência de desejos, necessidades, interrogações, alegrias, fantasias, angústias e medos próprios dessa fase do desenvolvimento humano.

Estudos produzidos por diferentes áreas do conhecimento revelam a importância dessa etapa da vida e, nesse contexto, o diálogo com a experiência desenvolvida pelo Instituto Emmi Pikler e com os princípios defendidos por Marie-Claire Busnel e Françoise Morel se complementa e evoca vislumbrar um bebê que se expressa e tem muito a nos dizer.

Nesse sentido, a autoavaliação, com todos os segmentos envolvidos num único propósito (o do bem-estar dos bebês e das crianças pequenas) mobiliza-os a querer saber de que forma a participação ativa do adulto contribui para estimular a livre expressão, garantindo assim que as vozes infantis prevaleçam nas decisões dos adultos.
3. A cor verde indica um trabatho consolidado, o amarelo representa a necessidade de uma atenção concentrada e o vermelho alerta para a ausência de ações. 
Durante a aplicação da autoavaliação, a metodologia das cores (verde, amarelo e vermelho) ${ }^{3}$ oferece aos indicadores um parâmetro de como os participantes podem considerar cada pergunta refletindo no panorama de como vai o atendimento, mas também pode ocultar o retrato da unidade e vir a não traduzir a realidade do cotidiano.

\footnotetext{
"Quando se atribui a cor verde a situações que a plenária julgou amarela ou vermelha, sendo que a solução depende de demanda externa para a melhoria do indicador em discussão. Nesse aspecto o documento revelou a dificuldade dos participantes no processo coletivo de se colocarem corresponsáveis nas ações" (NASCIMENTO, 2016, p. 128).
}

Em consonância a essa proposta, Anna Bondioli aponta para a necessidade de reconhecer que dissensos fazem parte da ideia de que a qualidade tem uma natureza negociável; significa não legitimar um ponto de vista em detrimento de outro, mas reconhecer a natureza valorativa da qualidade, considerando que, para isso, o embate de ideias não deve levar a constrangimentos, mas ser um recurso construtivo para todos os envolvidos.

As reflexões feitas no presente artigo, à luz do documento Indicadores de Qualidade da Educação Infantil Paulistana (2016), das contribuições com as experiências em avaliação participativa, das discussões sobre a qualidade na primeira infância e de autores que elucidam a importância de vislumbrar uma prática pedagógica embasada nas concepções contemporâneas sobre os bebês, crianças e infância, nos possibilitaram constatar a necessidade de um currículo que contemple o desenvolvimento integral de crianças nas dimensões propostas, na sua indivisibilidade.

Com a aplicação dos Indicadores de Qualidade da Educação Infantil Paulistana (2016), os dados revelaram que o uso do documento potencializa a creche como um espaço onde os adultos aprendem entre si. Quando a unidade encaminha suas ações no entendimento de que a participação está a serviço da qualidade, mais facilmente os pais sentem-se mobilizados. Aspectos que vão além de estarem presentes na unidade, mas de serem tomados pela consciência de que suas ações contribuem com a educação de cada bebê e criança no espaço coletivo. Nesse cenário, os adultos que respondem às perguntas dos indicadores com comentários sobre as suas próprias percepções proporcionam a outros pais, mesmo aqueles que desconhecem a rotina, a possibilidade de conhecerem e terem vontade de entender melhor a unidade. Bondioli (2013) ressalta que esse espaço reconhecido pelos pais é um lugar de responsabilidade não só pelos próprios filhos, mas 
pela instituição e pela comunidade, onde se constroem os saberes compartilhados, fruto de um trabalho participativo.

0 detalhamento das questões gerou comentários de descrença, inclusive pelo tempo investido em toda a aplicação, mas, em contrapartida, os participantes reconheceram que oportuniza conhecer o que é feito ou não na creche, a troca de exemplos concretos, no compartilhamento dos conhecimentos sobre a educação, auxiliando-os nas atitudes com os filhos em casa e na unidade, característica que potencializa o documento em momentos de estudo e formação com os professores.

Tais constatações estão garantidas na metodologia do documento norteado por dois princípios: o princípio dos direitos fundamentais das crianças e o princípio da participação (SÃO PAULO, 2016). Dessa forma, a unidade dispõe de um instrumento para além de avaliativo, sendo este um material de uso contínuo por todos os segmentos participantes, legitimando a busca da qualidade em ações que fortaleçam "a possibilidade de construir compartilhando essa responsabilidade" (BONDIOLI, 2013, p. 59).

A metodologia das cores subsidia as respostas dos participantes, que atribuem uma cor às perguntas de cada indicador. Essa prática não isenta os participantes das discussões, mas os possíveis caminhos ofertados por esse processo de atribuição de cores de fato dão aos participantes o "empoderamento" para efetivar sua participação. Levando em conta quaisquer aspectos que impeçam a manifestação oral, sendo de cunho individual ou nas relações confusas na própria unidade, as cores agem no momento da discussão como a resposta objetiva para o indicador. Em contrapartida, a cor pode esconder as reais condições, desafio este atrelado a reconhecer e a validar que, se um indicador é sinalizado com prioridade de atenção, a avaliação deve ser fiel e coerente com as dificuldades expostas, caso contrário dificulta a ação coletiva em busca de melhoria da qualidade esperada. 0 encaminhamento da metodologia para atingir os resultados, considera que a "avaliação sincera ajuda a resolver problemas" (MEC, 2009, p. 23).

As preocupações expostas neste artigo foram ratificadas pelas pesquisas em relação à formação dos educadores da primeira infância e, em especial, de bebês, nas quais constatou-se a não compreensão dos conceitos relacionados à intencionalidade pedagógica de um currículo que contempla os saberes próprios dos bebês, baseado na escuta, na observação e na transformação do espaço em ambiente e como este interfere de maneira significativa 
na aprendizagem infantil. Isso vem à tona nos resultados obtidos especificamente na nova dimensão nomeada pelo grupo de trabalho da rede como Participação, escuta e autoria de bebês e crianças.

O uso equivocado da metodologia das cores deflagra a ausência de uma "avaliação sincera" proposta pelo documento nacional (2009), ultrapassando os limites de coerência quando se trata, retomando, de um dos princípios do documento: o princípio dos direitos fundamentais das crianças (SÃO PAULO, 2016). Dito de outra forma, na atribuição da cor para os indicadores dessa dimensão, o verde prevaleceu em muitas experiências de autoavaliação participativa em creches na rede municipal de São Paulo.

As possibilidades que o documento revela com esse instrumento avaliativo são as discussões coletivas no sentido de reconhecer as lacunas da formação dos professores que emergem na própria unidade, a partir, por exemplo, dos resultados da autoavaliação de cada realidade, que se propõe com o seu uso a várias formas de utilização. Como sugerido pelos profissionais da rede, o material é importante para reuniões pedagógicas, de pais e de formação. Embora a utilização seja muito recente na Educação Infantil, as reflexões por parte das equipes das unidades contribuem para se constatar que o "esverdeamento" e a "conspiração do verde", como nomeado por participantes da aplicação, estão chamando a atenção para ações pontuais de mudança e transpor práticas pela via do desvelamento dos não saberes.

\section{REFERÊNCIAS}

ANDRÉ, R.C. Creche: Desafios e possibilidades. Um olhar para além do educar e cuidar. Dissertação (Mestrado) - Faculdade de Educação, Pontifícia Universidade Católica de São Paulo, São Paulo, 2016.

BONDIOLI, Anna (org.). O projeto pedagógico da creche e a sua avaliação. Campinas: Autores Associados, 2004.

BONDIOLI, Anna; SAVIO, Donatella (Org.). Participação e qualidade em educação da infância: percursos de compartilhamento reflexivo em contextos educativos. Tradução Luiz Ernani Fritoli. Curitiba: UFPR, 2013. 
BRASIL. Constituição da República Federativa do Brasil. Brasília, 1988.

BRASIL. Diretrizes Curriculares Nacionais para a Educação Infantil. Resolução n. 1, de 7 de Abril de 1999. Brasília: MEC/ CEB, 1999.

BRASIL. Presidência da República. Lei n. 8.069, de 13 de julho de 1990. Dispõe sobre o Estatuto da Criança e do Adolescente e dá outras providências. Disponível em: http://www. planalto.gov.br/ccivil_03/leis/l8069.htm. Acesso em: 08 dez. 2014.

BRASIL. Ministério da Educação. Indicadores da qualidade na Educação Infantil. Brasília: Secretaria de Educação Básica, 2009.

BRASIL. Presidência da República. Lei n. 9.394, de 26 de dezembro de 1996. Dispõe sobre a Lei de Diretrizes e Bases da Educação Nacional (LDBN). Disponível em: <http://portal. mec.gov.br/arquivos/pdf/ldb.pdf>. Acesso em: 20 fev. 2015.

BRASIL. Ministério da Educação. Parâmetros nacionais de qualidade para a Educação Infantil. Brasília: Secretaria de Educação Básica, 2008. v.2.

BUSNEL, Marie-Claire. A linguagem dos bebês. São Paulo: Escuta, 1997.

CORSINO, Patrícia. Educação Infantil: cotidiano e políticas. Campinas: Autores Associados, 2009.

LIMA, Licínio C. A Escola como organização educativa: uma abordagem sociológica. São Paulo: Cortez, 2011.

LÜDKE, M.; ANDRÉ, M.E.D.A. Pesquisa em Educação: abordagens qualitativas. Rio de Janeiro: E.P.U., 2013.

NASCIMENTO, A.D. Autoavaliação institucional participativa: uma experiência em duas creches da rede municipal de São Paulo. 2016. Dissertação (Mestrado) - Faculdade de Educação, Pontifícia Universidade Católica de São Paulo, São Paulo, 2016. 
SÃO PAULO (SP). Secretaria Municipal de Educação. Avaliação na Educação Infantil: aprimorando os olhares. São Paulo: SME / DOT-EI, 2014.

SÃO PAULO (SP). Secretaria Municipal de Educação.

Indicadores de Qualidade da Educação Infantil paulistana.

São Paulo: SME / DOT-El, 2016.

Recebido em: 30/09/2016

Revisto em: 04/11/2016

Aceito em: 09/11/2016 